\title{
A aprendizagem ubíqua na educação aberta
}

\author{
Lucia Santaella
}

\section{Resumo}

As mídias digitais vieram para embaralhar as cartas do jogo, em todos os campos do social, político, cultural, comunicacional, educacional com repercussões no psiquismo, nos modos de pensar e conhecer, nas disposições para agir e nas formas de perceber e sentir e interagir. Não há qualquer reduto da vida humana que tenha ficado incólume à voragem digital. As redes digitais se constituem não só em malhas de comunicação planetária, por onde perpassam compartilhamentos, solidariedades, controvérsias e conflitos, mas, sobretudo, constituem-se em espaços de difusão e acesso à informação e saberes. Não há conhecimento sem comunicação, nem comunicação sem midiatização das informações e dos dispositivos. Potencializando os processos de comunicação e acesso, as redes potencializam também as fontes e práticas de conhecimento, assim como incrementam o estabelecimento de ambientes de aprendizagem e a partilha de saberes e competências. Este artigo pretende discutir o papel que a aprendizagem ubíqua pode desempenhar no contexto de práticas e recursos educacionais abertos.

Palavras-chave: Redes, aprendizagem, educação aberta, midiatização

\footnotetext{
* Pesquisadora 1 A do CNPq, graduada em Letras Português e Inglês. Professora titular no programa de Pós-Graduação em Comunicação e Semiótica da PUCSP, com doutoramento em Teoria Literária na PUCSP em 1973 e Livre-Docência em Ciências da Comunicação na ECA/USP em 1993. É Coordenadora da Pós-graduação em Tecnologias da Inteligência e Design Digital, Diretora do CIMID, Centro de Investigação em Mídias Digitais e Coordenadora do Centro de Estudos Peirceanos, na PUCSP. É presidente honorária da Federação Latino-Americana de Semiótica e Membro Executivo da Associación Mundial de Semiótica Massmediática y Comunicación Global, México, desde 2004. É correspondente brasileira da Academia Argentina de Belas Artes, eleita em 2002. Foi eleita presidente para 2007 da Charles S. Peirce Society, USA. E-mail: Ibraga@pucsp.br
} 


\section{El aprendizaje ubicuo en la educación abierta}

Resumen

Los medios digitales llegaron a barajar las cartas del juego, en todos los ámbitos del social, político, cultural, comunicacional, educativo con repercuciones en el psiquismo, en los modos de pensar y conocer, en las disposiciones para actuar y las maneras de percibir y sentir e interactuar. No hay bastión de la vida humana que se ha quedado indemne a la vorágine digital. Las redes digitales se constituyen no sólo en redes de comunicación global, por donde permean acciones, solidaridades, controversias y conflictos, pero, sobre todo, se constituyen en espacios de difusión y acceso a la información y saberes. No hay conocimiento sin comunicación, ni comunicación sin cobertura de los medios de comunicación de la información y de los dispositivos. Potenciando los procesos de comunicación y acceso, las redes pontencian también las fuentes y prácticas de conocimiento, así como incrementan la creación de ambientes de aprendizaje y el intercambio de conocimientos y habilidades. En este artículo se analiza el papel que el aprendizaje ubicuo puede desempeñar en el contexto de las prácticas y recursos educativos abiertos.

Palabras clave: redes, aprendizaje, educación abierta, mediatización

\section{PeUbiquitous learing in open education}

The digital media came to shuffle the cards of the game, in all the social, political, cultural, communicational, educational fields, impacting the psyche in the ways of thinking and knowledge acquirement, in the dispositions to act, in the ways to perceive, feel, and interact. There is no bastion of human life that has remained untouched by the digital abyss. Digital networks are composed not only by planetary communication permeated by information sharing, acts of solidarity, controversial issues, solidarities and conflict, but above all by spaces of dissemination and access to information and knowledge. There is no knowledge without communication, and there is no communication without information and devices permeated by the media. By enhancing communication processes and the access to information, networks also increase the sources and knowledge practicies, as well as it increases the establishment of learning environments as well as knowledge and skills sharing. This article discusses the role that ubiquitous learning can play in the context of open educational practices and resources.

Key words: Networks, learning, open education, media 
Perto de vinte anos atrás, quando a internet estava apenas emergindo no cotidiano de nossas vidas, em uma participação relâmpago em um debate promovido pelas escolas particulares de São Paulo, no tempo de poucos minutos, tentei dar meu recado veemente sobre as mutações que o universo digital estava fadado a trazer para os ambientes escolares. Durante todo o século XX, a educação permaneceu fiel à sua hegemonia gutenberguiana. O livro, as apostilas, enfim, o texto impresso, aliado à fala do professor, todos eles cumpriam sua função de transmissão privilegiada do saber.

O universo apelativo da comunicação de massa, especialmente a televisão, exercia grande força de atração sobre seus receptores. Mas o mundo, naqueles tempos, dividia-se em duas grandes áreas pouco intercomunicantes: a aquisição do conhecimento e a aprendizagem cujas fontes privilegiadas se encontravam na escola, de um lado, e, de outro lado, o entretenimento e distração centrados na televisão, revistas, cinema e mesmo o rádio. É certo que o jornal, rádio, telejornal cumpriam a função de transmitir notícias e informação. É certo que, nas suas grades de programação, a televisão e o rádio levavam à frente uma minoritária função educativa. Mas isso não chegava a abalar os polos perfeitamente separados e distintos entre a seriedade da vida, nos ambientes de ensino e aprendizagem, e a esperada diversão, para fora dos muros da escola.

Quando a internet começou a despontar, ela já prometia embaralhar esse jogo de forma radical. Isto porque já continha no seu bojo uma mistura inédita entre fontes de informação e entretenimento. Ou seja, sua constituição de infotenimento. Para completar, muito rapidamente, o computador se converteu em metamídia de interação e comunicação, reconfigurando drasticamente as dimensões de espaço-tempo da existência humana. De lá para cá, as transformações tecnológicas do digital colocaram cada vez naus sua mira no usuário disponibilizando terabytes de conteúdo na palma de sua mão ao toque de uma escolha. De fato, a mais revolucionária dentre essas transformações tomou o rumo dos dispositivos móveis, numa relação equitativa entre o tamanho mínimo do equipamento onipresente junto ao corpo e o poder máximo de sua capacidade de transmissão e disseminação.
Ora, não há aquisição de conhecimento, tarefa precípua da educação, que não dependa da materialidade dos suportes de registro dos conteúdos que permitem essa aquisição. Quando esses suportes estão à mão e disponíveis à livre escolha do usuário, é toda a tradição secular dos recursos e práticas educacionais, especialmente a condição de reclusão do educando no espaço escolar, que rui como um castelo de areia.

\section{O ser humano que emerge com as redes digitais}

No seu livro, Redes ou paredes. A escola em tempos de dispersão, Paula Sibília (2012, p. 177) nos oferece um diagnóstico precioso sobre as contradições e dilemas em que os processos educacionais estão hoje imersos diante do fato de que crianças e jovens driblam com invejável competência "eventuais proibições das hierarquias escolares", pois costumam recorrer às conexões nas redes "para sobreviver à chatice" de "passar boa parte de seus dias encerrados nas salas de aula, mais desesperadamente desconectados que disciplinarmente confinados". A autora pergunta: "qual é a capacidade de a escola resistir a semelhante mutação?" (...) Será que sua "estrutura envelhecida estará em condições de se adaptar às novas regras do jogo, transformando-se de um modo efetivo e interessante?". (ibid., p. 179)

Compartilhando as preocupações da autora, em pesquisas voltadas com ênfase para as transformações cognitivas, perceptivas, sensoriais e motoras que afetam os usuários das redes, fui desenvolvendo ao longo de alguns anos, o conceito de leitor imersivo (Santaella, 2004) e, mais recentemente, o de leitor ubíquo, questão que me parece fundante para se compreender que novo ser humano é esse que os educadores têm hoje diante de si. Do conceito de leitor ubíquo, derivei o consequente conceito de aprendizagem ubíqua (ibid. 2013).

Tanto o leitor imersivo quanto o ubíquo são partes de uma classificação que engloba quatro tipos de leitores: o contemplativo é o leitor do livro, que realiza seu ato de modo solitário e concentrado, concentração que é imprescindível aos roteiros da memória de que depende a aprendizagem e aquisição de conhecimento. 
O leitor movente aprendeu a sincronizar sua marcha perceptiva e motora com a velocidade e o burburinho frenético das grandes metrópoles. Nos seus processos de orientação entre sinais, setas, cores, luzes e movimento de que o mundo urbano está povoado, esse leitor foi adaptando sua sensibilidade perceptiva para a leitura das imagens em movimento do cinema e dos cortes abruptos da linguagem televisiva.

O leitor imersivo é aquele que navega pelas configurações reticulares da informação nas redes, saltando de um conteúdo multimidiático a outros no instantâneo de um toque. O ubíquo deriva do imersivo e brotou tão logo se tornou usuário dos dispositivos móveis os quais lhe propiciaram a possibilidade de acessar as redes e se comunicar com seus pares e mesmo ímpares de qualquer lugar e em quaisquer momentos.

Uma vez que já discorri sobre o perfil cognitivo desse novo tipo de leitor (Santaella, 2013, p...), limito-me aqui a uma síntese que permita a passagem para a definição das características do que chamo de aprendizagem ubíqua. Esse leitor vive nos espaços da hipermobilidade, ou seja, da sua mobilidade física somada à mobilidade com que transita pelas redes de informação, comunicação e troca. Em simultaneidade e com extrema destreza orienta-se mentalmente, portanto, entre dois espaços: aquele do movimento do seu corpo e aquele das rápidas operações cognitivas necessárias à interação nas redes.

Não é difícil perceber que esse leitor mistura traços do leitor movente com o leitor imersivo. Ao mesmo tempo em que lê e responde aos sinais e signos do seu entorno físico também imerge no ciberespaço informacional. Consequentemente, o que o caracteriza é uma inédita prontidão motora, perceptiva, cognitiva e uma nova economia da atenção derivadas de um modo distinto de funcionamento do seu sistema nervoso central. Ora, esse tipo de leitor está sendo protagonista de um modo também novo de aprender. Um tipo de aprendizagem que se obtém nos instantâneos dos velozes acessos às redes na colheita de informações ocasionais.

\section{O que é aprendizagem ubíqua}

O conceito de aprendizagem, como quase todos os conceitos, está longe de ser simples. Para não nos enveredarmos nessa discussão, recupero aqui uma definição que, a meu ver, está pouco sujeita a controvérsias e que permitirá nos dirigirmos para a questão da aprendizagem por meio das redes e nas redes. Davenport e Prusak (1998, apud Liaw et al. 2010, p. 447) consideram que "o conhecimento é uma mistura fluida de experiência emoldurada, valores, informação contextual e insight experto que fornece uma moldura para avaliar e incorporar novas experiências e informações". Ora, não há conhecimento, sem aprendizagem. Partindo do princípio de que o processo de aprendizagem implica ativamente encontrar e recuperar conhecimento como resultado da interação com os ambientes de aprendizagem, então a aquisição de conhecimento é um processo interativo que as redes digitais intensificam (Barker, 2005, apud Liaw, ibid., p. 449).

Por que intensificam? A interatividade é a característica central de toda a cultura do computador. Se não desenvolvermos treinamento, de que tipo for, por experimentação ou por orientação, para o uso das interfaces no mundo de múltiplas telas que nos é oferecido, as telas permanecem em escuro silêncio. Portanto, o uso depende aí, sine qua non, da interação não apenas mental quanto também motora, na mais perfeita sincronia entre operações perceptivo-cognitivas e destreza corporal, especialmente viso-tátil-manual. Esse tipo de interatividade implica navegar através do corpus de informação eletrônica, controlando como essa informação é disponibilizada na tela, facilitando a flexibilidade e permitindo respostas dinâmicas no diálogo entre o humano e a inteligência computacional e informacional das redes. Ora, essas interfaces acionadas pela interatividade não só abrem as portas e janelas para o acesso aos labirintos da informação, mas também funcionam como mídias comunicacionais.

Mídias móveis propiciam que tudo isso seja agenciado de qualquer lugar para qualquer lugar e em quaisquer momentos, portanto, acesso ubíquo à informação, à co- 
municação e à aquisição de conhecimento. Além disso, os recursos móveis oferecem conectividade individualizada e personalizada o que intensifica a colaboração em tempo real ou interatividade instantânea que pode permitir melhores tomadas de decisão. Isso facilita e instiga a constituição e coesão de grupos informais de interesses e preocupações comuns. Quando compartilhados, os interesses unem as pessoas, no sentido de que ajudam a desenvolver nelas um estado de prontidão para a colaboração e para a ajuda mútua. Sendo ubíquos o acesso, os contatos e as trocas, aceleram-se as possibilidades de aquisição de conhecimento e, de certo modo, a espontaneidade e naturalização de sua absorção.

Se a aquisição do conhecimento implica a aprendizagem, o que brota aí é aquilo que venho chamando de aprendizagem ubíqua e o tipo de aprendizado que se desenvolve é aberto, individual ou grupal, podendo ser obtido em quaisquer ocasiões, eventualidades, circunstâncias e contextos. Sua característica mais marcante encontra-se na espontaneidade. Em qualquer lugar que o usuário esteja, brotando uma curiosidade ocasional, esta pode ser instantaneamente saciada e, se surgir uma dúvida a respeito de alguma informação, não faltam contatos pessoais também instantâneos para resolvê-la, criando-se assim um processo de aprendizagem colaborativa.

Sem restrições de tempo e espaço, sem pressões externas, coloco ênfase na espontaneidade livre que aciona todo esse processo. Trata-se de uma busca e de uma aquisição de informação a céu aberto e fora de quaisquer planejamentos e sistematizações, portanto, o que se tem aí é uma forma de aprendizagem imprevisível, dispersiva, fragmentária e mesmo caótica, nem sempre incorporada à memória. No entanto, inegavelmente aprendizagem, na medida em que o conhecimento que ela traz, antes inexistente, adquire agora a possibilidade, nem sempre efetivada -- isto também é inegável -- de ser incorporado ao repertório do aprendiz. E a única prova que se tem de que ele foi incorporado ou não é quando surgir a ocasião de colocá-lo em prática, único tipo de avaliação a que a aprendizagem ubíqua pode se submeter.

Embora seja um tipo de aprendizagem recente e, portanto, novo, ele está, até certo ponto, aparentado com outras formas de aprendizagem em rede, on line, com os processos educacionais que vêm sendo chamados de $e$ -learning e m-learning (ver Santaella 2013, p. ). Mas a espontaneidade livre e aberta, que lhe caracteriza, coloca a aprendizagem ubíqua bem próxima da educação informal, dos processos de autoformação mais tradicionais. Todavia, mesmo neste caso, as distinções são notáveis.

O que une todas essas tendências é que elas se inserem dentro do contexto da educação aberta. Comecemos por esse contexto para, então, evidenciar as sutis distinções entre a aprendizagem ubíqua e essas outras formas de aprendizagem.

\section{Formações e práticas abertas}

Para começar, pode-se dizer que a educação é aberta quando ela é livre, quando ela permite outros voos e outras produções, quando inclui a remixagem e, por fim, quando entende a diferença entre um valor a ser enaltecido e não simplesmente aceito ou considerado (Santana, Rossini e Pretto, 2012, p.13).

De acordo com Santos (2012, p. 71), não é fácil precisar o início do uso do conceito de educação aberta. Hoje, ele é utilizado "no contexto dos chamados Recursos Educacionais Abertos (REA), trazendo consigo uma gama de novas práticas de ensino-aprendizagem que se popularizaram com o advento das tecnologias educacionais". A autora nos fornece uma sequência de definições e práticas que abrangem a liberdade do estudante, o estudo por módulos, a utilização de autoinstrução, a isenção de barreiras prévias, o acesso a possíveis deficiências e a provisão de recursos educacionais abertos.

Após a discussão da educação aberta no contexto infantil e da educação superior, Santos (p. 80-82) apresenta um elenco de expressões e contextos em que a educação aberta se manifesta, tais como, educação aberta, aprendizagem aberta, aprendizagem a distância ou educação a distância, recursos educacionais abertos, práticas educacionais abertas, educação inclusiva, acesso aberto, licença aberta, código aberto, open courseware, e-learning ou aprendizagem virtual, aprendizagem móvel (m-learning), curso aberto on line em massa. 
A mera nomenclatura já permite a inferência de que se trata de um tipo de educação e aprendizagem que se incrementou grandemente graças às tecnologias digitais e uma das características principais dos REA, apontadas pela autora, encontra-se na presença da licença aberta que potencializa "o potencial de compartilhamento de conhecimento entre autores e usuários, de uma forma global, sem a preocupação em infringir direitos autorais" (p. 83). Dois são os fatores que contribuíram para novas maneiras de interagir com o conteúdo: a passagem das plataformas unilaterais para as multidirecionais, colaborativas e interativas, a ubiquidade da internet, a sofisticação da telefonia moderna e a consequente expansão da aprendizagem aberta para uma abrangência global. O segundo fator refere-se à "emergência de novas formas de licenciamento para conteúdo digital, que abriu novos horizontes para a distribuição e utilização de materiais educacionais" (p. 84). Para Amiel (2012, p. 18),

O movimento para uma Educação Aberta é uma tentativa de buscar alternativas sustentáveis para algumas das barreiras evidentes no que tange ao direito de uma educação de qualidade. Nessa perspectiva, o conceito de "abertura" não é necessariamente dependente de desenvolvimentos tecnológicos e antecede a popularização de dispositivos digitais, da internet e da web, mas pode ser fortalecida por novas mídias.

Isso não implica, simplesmente, aderir ao dernier cri das tecnologias e escolher quais novas mídias seriam capazes de suplantar modelos de ensino vigentes, numa declaração de guerra entre o velho e o novo. Sem negar que se trata de um embate, ele nada tem de binariamente extremista, mas sim da busca por configurações cada vez mais complexas de ensino e aprendizagem, ou seja, uma proposta de educação aberta que visa

Fomentar (ou ter a disposição) por meio de práticas, recursos e ambientes abertos, variadas configurações de ensino e aprendizagem, mesmo quando essas aparentam redundâncias, reconhecendo a pluralidade de contextos e as possibilidades educacionais para o aprendizado ao longo da vida. (ibid., p. 19).

Lembrando que a web não é um simples instrumento de difusão da informação, mas "uma verdadeira tec- nologia intelectual, uma ferramenta cognitiva no sentido pleno" (Alava, 2002, p. 16), é preciso notar que o universo digital, em toda sua imensurável extensão e diversidade, passou a funcionar como uma alavanca para a evolução contínua das práticas educacionais, colocando os professores diante de uma necessária nova dinâmica de formação para enfrentar o contundente problema do adquirido poder do aprendiz e de seu controle sobre os processos de autoformação. Portanto, falar em educação aberta hoje implica considerar que ela é inseparável de todos os recursos e práticas que a educação a distância foi descortinando ao acompanhar pari passu as céleres evoluções dos dispositivos tecnológicos. Implica, consequentemente, levar em consideração o que estou chamando de aprendizagem ubíqua e sua diferença crucial em relação a outras práticas e recursos do elenco da educação aberta.

\section{Semelhanças e diferenças}

Desde a publicação do livro, tanto quanto sei, pioneiro no Brasil, Sala de aula interativa, de Marco Silva (2000), o campo daquilo que, até então, era chamado de educação a distância, começou a se abrir, cada vez mais, para abrigar questões e desafios que o mundo digital não cessa de apresentar para a educação. De lá para cá, existe um volume considerável e significativo de literatura, publicado por pesquisadores brasileiros da área de educação, responsavelmente engajados na apresentação de reflexões teóricas e críticas, assim como propostas práticas sobre questões candentes.

Os temas dessas publicações evidenciam a pletora de problemas que são levantados os quais abrangem a informática para a educação a distância (Moraes, org., 2002), teorias e práticas da educação a distância (Rodrigues e Carvalho, orgs., 2011), a gestão e docência da educação a distância (Oliani e Moura, orgs., 2012), educação virtual (Muller et al., orgs., 2013), educação on line (Silva, Pesce e Zuin, orgs., 2010), formação de professores para a docência on line (Silva, org. 2012).

O campo da educação on line visa se alinhar ao crescimento da web indo além, portanto, das modalidades de educação via meios unidirecionais, como o rádio e a TV. 
Enquanto a modalidade via meios unidirecionais separa emissão e recepção no tempo e no espaço, a modalidade on line conecta professores e alunos nos tempos síncrono e assíncrono, dispensa o espaço físico, favorece a convergência de mídias e contempla bidirecionalidade, multidirecionalidade, estar junto "virtual" em rede e colaboração todos-todos (Silva, Pesce e Zuin, 2010, p. 11).

$\mathrm{Na}$ educação on line, são discutidos problemas relativos, por exemplo, ao desenho didático, à metodologia, à avaliação na formação on line, educação e redes sociais, aprendizagem em ambientes virtuais, e-learning e também m-learning. Estas últimas se constituem em formas de aprendizagem que se aproximam a ponto de se confundir com a aprendizagem ubíqua. A e-learning é uma abreviação de eletronic learning, ou seja, aprendizagem por meio eletrônico. É o nome que se costuma dar para os processos de aprendizagem que dependem do uso de computadores e seus programas voltados para essa finalidade. Ao ser disponibilizado na internet, o material de ensino-aprendizagem pode ser acessado a qualquer hora e de qualquer lugar do mundo, não havendo outra barreira para isso a não ser a concessão de licença e também a barreira da língua. Por isso, o discurso sobre e-learning costuma ser aliado à difusão do conhecimento e à democratização do saber.

A m-learning, aprendizagem móvel, por sua vez, refere-se ao uso de dispositivos portáteis e, portanto, ubíquos que dependem de redes sem fio e telefonia móvel para apoiar, facilitar e enriquecer o ensino-aprendizagem. Estamos aqui muito perto da aprendizagem ubíqua, pois certamente a m-learning é ubíqua na medida em que faz uso de dispositivos ubíquos. Entretanto, se a m-learning é utilizada no contexto de recursos e práticas que se incorporam a processos educacionais, esse fator marca a distinção entre m-learning e aprendizagem ubíqua, uma vez que esta última é livre, solta, ocasional. Quer dizer, trata-se de uma aprendizagem que transfere para o aprendiz completa autonomia sobre seu aprendizado.

Portanto, à primeira vista, essa condição de autonomia, coloca a aprendizagem ubíqua no elenco da autoformação que é própria da educação informal, tal como ocorre quando o indivíduo, por livre e espontânea vontade, visita museus, casas de cultura, bibliotecas, centros de documentação, espaços de livres serviços etc. Nestes casos, contudo, a aprendizagem não é ubíqua, implicando um deslocamento no espaço para esses locais, além de que essas visitas se dão porque existe uma intencionalidade, uma busca em querer se instruir.

A aprendizagem ubíqua, por sua vez, pode se dar em quaisquer circunstâncias, a qualquer momento, em qualquer lugar. Ela se dá sempre no aqui e agora, sendo, por natureza, dispersa, casuística, o que pode levar muitos a negar que haja aí processos de aprendizagem. Afirmo que há. Embora seja um processo bem distinto daquilo que costuma ser chamado de aprendizagem como fecundação do conhecimento como guia para a ação deliberada, coerente e eficaz no mundo da vida social, a aprendizagem ubíqua é prenhe de lampejos de aprendizagem, funcionando também como estopim da aprendizagem quando uma informação fisga o interesse do usuário, levando-o a caminhar dentro dela até seus meandros mais recônditos e especializados.

Desde que comecei a engatinhar nessa questão da aprendizagem ubíqua, provavelmente há uns quatro anos, já sabia com alguma certeza de que se trata de um tipo de aprendizagem que não poderia, de modo algum, nem agora nem no futuro, substituir a educação formal fechada ou aberta. Qual é, então, o papel que cabe à aprendizagem ubíqua?

\section{O papel da aprendizagem ubíqua}

Existe perto de um consenso de que, diferentemente do que pensam os mais apressados, as tecnologias da inteligência não nos levarão ao fim da escola rumo à plena autonomia e controle do educando na sua autoformação. Em relação ao mundo infantil, de saída, a consideração positiva dessa hipótese soaria absurda além de ridícula. Crianças não se ensinam a si mesmas. Se existe ainda alguma dúvida sobre o mundo adulto, há alguns pontos a se considerar.

Antes de tudo, vale lembrar Paulo Freire, quando dizia que "a escola deve estar à altura do seu tempo, e, para 
tal, não é preciso sepultá-la, mas ... refazê-la" (apud Amiel, 2012 , p. 22). Portanto, jogar fora as lições do passado frente aos avanços da tecnologia significa descartar a necessidade de ressignificar a escola, o ensino, as estratégias e todos os fatores neles implicados.

Em segundo lugar, existe um grande desequilíbrio entre a gigantesca difusão da informação e do conhecimento nas redes e a aquisição individual daquilo que é difundido. "O ciberespaço é um espaço em constante mutação, em conflito e em regulamentação" (Alava, 2002, p. 21). Sobretudo, é um espaço que cresce exponencialmente. Sua utilização como alavanca do conhecimento não dispensa processos de ensino-aprendizagem responsavelmente aparelhados e formulados.

Em terceiro lugar, o campo virtual é volátil e dominado pela condição evanescente da informação. Para domar minimamente essa evanescência é preciso desenvolver estratégias ativas de apropriação, o que é tarefa precípua da escola, pois sua realização individual seria sumamente lenta e árdua. Para Corea (apud Sibilia, 2012, p. 185), "qualquer conexão produz efeitos dispersivos" de modo que "sem princípio de autoridade, nem código estabelecido, toda conexão com o fluxo, toda intervenção produz uma multiplicidade dispersa de efeitos" e consequente fragmentação.

Embora possa intensificar os circuitos de autoformação, evidentemente, a aprendizagem ubíqua intensifica igualmente a pulverização do aprendizado, na medida em que ela não está submetida a códigos e instituições. Consequentemente, o aproveitamento desse tipo de aprendizagem implica sua incorporação a procedimentos de m-learning aliados a um blending de recursos e práticas de educação aberta.

O mais importante, contudo, que me levou a prestar atenção a esse fenômeno inteiramente novo que chamo de aprendizagem ubíqua, é notar o quanto esse tipo de aprendizagem, embora dispersivo, fragmentário e pulverizador, transforma cognitivamente o ser humano no seu papel de potencializador da aprendizagem. O professor precisa ficar alerta a essa transformação de modo a estar minimamente preparado para os sobressaltos das surpresas que o aguardam nas interações com seu suposto aprendiz.

\section{Referências}

ALAVA, Séraphin. Os paradoxos de um debate. In Séraphin Alava et al (org.). Ciberespaço e formações abertas. Rumo a novas práticas educacionais, Fátima Murad (trad.). Porto Alegre: Artmed, 2002, p. 13-21.

AMIEL, Tel. Educação aberta: configurando ambientes, práticas e recursos educacionais. In Santana, Bianca; Rossini, Carolina; Pretto, Nelson De Luca. Recursos educacionais abertos. Práticas colaborativas e políticas públicas. Salvador: Casa da Cultura Digital/EDUFBA, 2012, p. 17-34.

MORAES, Maria Candida (org.). Educação a distância. Fundamentos e práticas. Campinas: Unicamp/Nied, 2002.

MULLER, Claudia C.; BASSANI, Fernanda; IAHN, Liciene Ferreira; SANTOS, Maria Luiza Fernandes B. dos. Inovações educativas e ensino virtual. Ponta Grossa: Estúdio Texto Ed., 2013.

OLIANI, Gilberto e MOURA, Rogério A. (orgs.). Educação a distância: gestão e docência. Curitiba: Editora CRV, 2012.

RODRIGUES, Cleide A. C. e CARVALHO, Rose Mary Almas de. Educação a distância: teorias e práticas. Goiânia: Editora da PUC Goiás, 2011.

SANTAELLA, Lucia. Navegar no ciberespaço. O perfil cognitivo do leitor imersivo. São Paulo: Paulus, 2004.

Comunicação ubíqua. Repercussões na cultura e na educação. São Paulo: Paulus, 2013.

SANTANA, Bianca; ROSSINI, Carolina; PRETTO, Nelson De Luca. Recursos educacionais abertos. Práticas colaborativas e políticas públicas. Salvador: Casa da Cultura Digital/EDUFBA, 2012.

SANTOS, Andreia Inamorato dos. Educação aberta: histórico, práticas e contexto dos recursos educacionais abertos. In In Santana, Bianca; Rossini, Carolina; Pretto, Nelson De Luca. Recursos educacionais abertos. Práticas colaborativas e políticas públicas. Salvador: Casa da Cultura Digital/EDUFBA, 2012, p. 71-90.

SIBILIA, Paula. Redes ou paredes. A escola em tempos de dispersão, Vera Ribeiro (trad.). Rio de Janeiro: Contraponto, 2012.

SILVA, Marco. Sala de aula interativa. Rio de Janeiro: Quartet, 2000.

SILVA, Marco (org.). Formação de professores para docência on line. São Paulo: Loyola, 2012.

SILVA, Marco; PESCE, Lucila; ZUIN, Antonio. Apresentação. In Silva, Marco; Pesce, Lucila; Zuin, Antonio (orgs.). Educação on line. Cenário, formação e questões didático-metodológicas. Rio de Janeiro: Wak editora, p. 11, 26.

Data de Recebimento: 10 de setembro de 2014

Data de Aprovação: 20 de outubro de 2014

Data de Publicação: 30 de dezembro de 2014 